\title{
Расширенное совещание руководителей предприятий радиоэлектронной промышленности
}

\author{
О. Казанцева
}

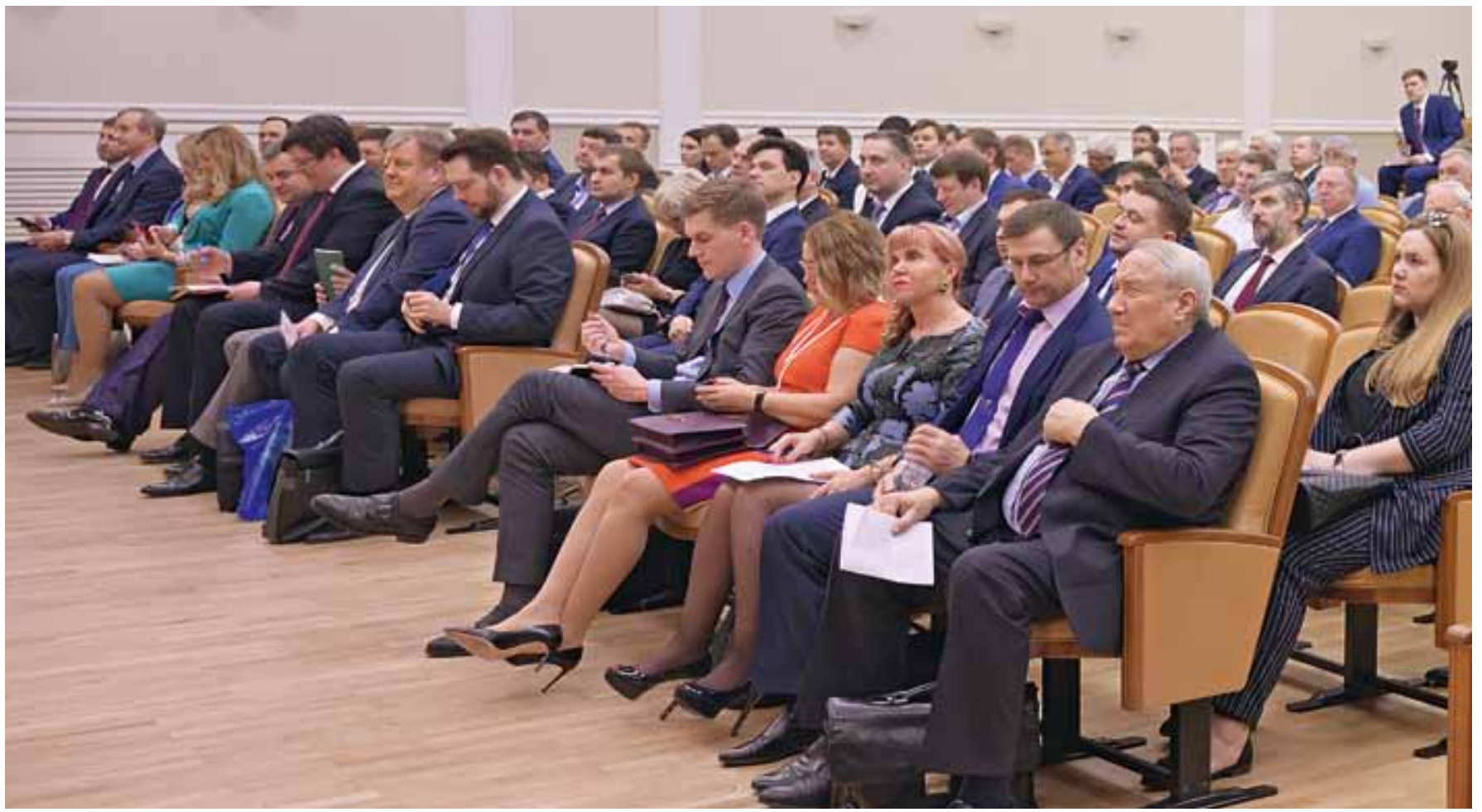

25 апреля 2019 года в МНИТИ под председательством члена-корреспондента РАН, генерального конструктора АО «Концерн "Вега" В. С. Вербы состоялось ежегодное расширенное совещание руководителей предприятий радиоэлектронной промышленности, посвященное обсуждению итогов деятельности радиоэлектронной промышленности в 2018 году и основных задач на 2019 год.

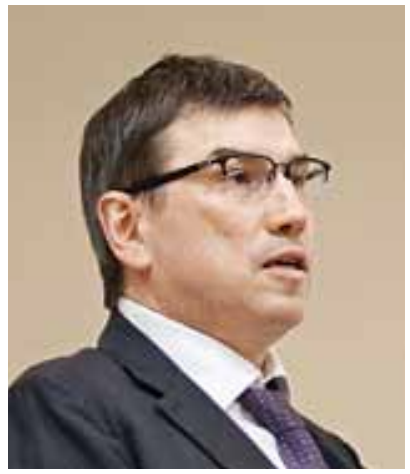

Во вступительном слове заместитель Министра промышленности и торговли Российской Федерации Олег Евгеньевич Бочаров отметил работу команды ДРэП под руководством С.В.Хохлова. Была предложена главная стратегически очень простая цель - создать реестр (именно реестр, а не перечень) отечественных приборов, для того чтобы замкнуть весь госзаказ и заказ государственных корпораций на этот реестр. Причем надо разбить реестр по подотраслям, сделать его автоматизированным. Тогда любой заказчик, где бы он ни находился и независимо от того, какую радиоэлектронную услугу он в свой заказ включает, уже не сможет при наличии отечественной ЭКБ использовать аналог иностранного производства, то есть не обойдет стороной отечественные разработки.

"я не знаю, насколько „живым“ получится этот инструмент. Это зависит от нас с вами. Сейчас мы вносим в реестр телекоммуникационное оборудование. Это самая мощная подотрасль. Именно сейчас телекоммуникационное оборудование востребовано во всех регионах РФ, так как оно обеспечивает информационную 
доступность государственных органов власти и бюджетных организаций", - сказал О. Е. Бочаров.

Планируется структурировать реестр по типам производимых предприятиями радиоэлектронного комплекса приборов и в течение года представить в нем целые разделы оборудования по всем сегментам рынка

Для эффективного выполнения этой работы всех производителей (ЭКБ, приборов, аппаратуры, программных продуктов, оборудования) предлагается разделить на подассоциации. По словам замминистра, «нам нужны не формальные объединения и ассоциации, а групповые - по типам приборов».

Индустриальный директор Радиоэлектронного комплекса ГК «Ростех» Сергей Степанович Сахненко: «Год был сложный, непростой, но это был переломный год в подходах и осознании того, что нам предстоит делать завтра, послезавтра, чтобы радиоэлектронная отрасль

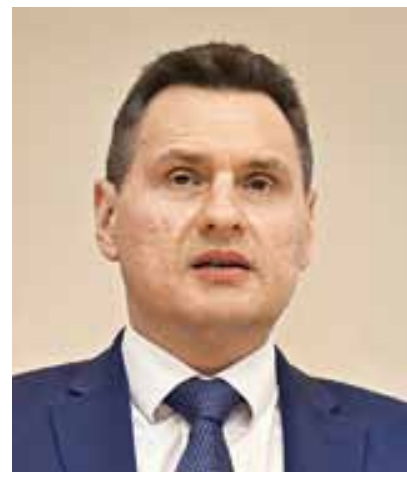
страны развивалась».

Как известно, динамика гособоронзаказа сегодня не обеспечивает требуемую динамику развития общества. Поэтому менеджмент на всех уровнях столкнулся с серьезным вызовом, связанным с необходимостью диверсификации.

Нам предстоит многое сделать. Прежде всего, важно изменить подходы к продуктовой стратегии. Вчера мы отталкивались от одного отдельно взятого продукта. А сегодня надо создавать системы и продавать комплексные инфраструктурные проекты. В этом случае можно будет гарантировать применение приборов, которые мы разрабатываем и серийно производим. Без изменения продуктовой стратегии сложно представить участие радиоэлектронных предприятий в реализации 12 национальных проектов, на которые государство намерено направить более 25 трлн руб. до 2024 года.

Что касается финансовых рынков в гражданском секторе, то мы активно работаем в этом направлении при поддержке Минпромторга России. Если говорить о конкуренции, то мы должны разрабатывать такие нормативно-правовые документы, в соответствии с которыми иностранным вендорам было бы выгодно производить свои продукты в Российской Федерации или они были бы обязаны это делать. Можно сказать, что разработанные нормативно-правовые документы и будут инструментом, который позволит создать условия для перехода к новому формату общения с ведущими мировыми разработчиками.
Помощник заместителя председателя Правительства Российской Федерации Ю.И. Борисова Андрей Владимирович Зверев передал участникам совещания приветствие от Ю.И.Борисова и его пожелание успешной работы директорскому корпусу. А. В.Зверев посето-

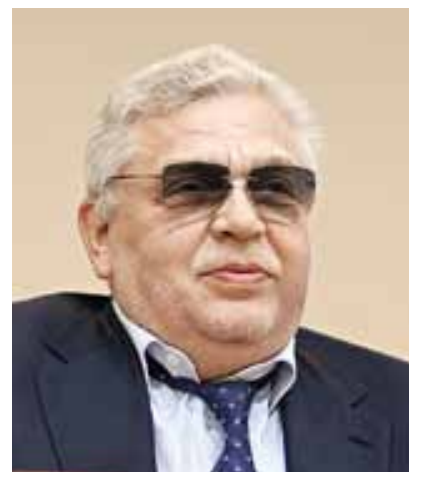
вал на то, что из года в год на расширенном совещании представители радиоэлектронной промышленности собираются не в полном составе (не пригласили профильные предприятия «Росатома" и «Роскосмоса»), и призвал отрасль к объединению, хотя бы идеологически, для эффективной конкуренции с зарубежными поставщиками

А. В. Зверев сообщил, что за последний год Ю.И. Борисов три раза встречался с Президентом страны и обсуждал вопросы развития радиоэлектроники. Государство уделяет большое внимание отрасли, которая является основой не только национальной безопасности, но и национального благополучия, движения вперед.

Недавно были приняты серьезные решения. Сдвинулось с мертвой точки строительство микроэлектронного производства в Зеленограде. Государство купило все акции 10-летнего проекта "Ангстрем-Т». Поставлена задача в кратчайшие сроки (примерно за полтора года) наладить производство микросхем по технологии 90-250 нм на пластинах диаметром 200 мм (производительность 15000 пластин в месяц). В дальнейшем будет создано производство на пластинах диаметром 300 мм по современным нормам (производительность - 2000 пластин в месяц). В рамках создания этих производств планируются разработка комплексных программ и развитие дизайнцентров для обеспечения выпуска микросхем любого типа. По оценкам специалистов, производительность может составить 25 млн микросхем в месяц.

На каком рынке будет востребовано такое количество микросхем?

На внутреннем рынке отечественные микросхемы составляют только 24\%. Каждый год мы ввозим (закупаем) микросхемы иностранного производства на 2 млрд руб. Конечно, надо менять такое положение.

Возможны два варианта: консолидируем отрасль, находим точки компетенции, ищем лидеров, которые сами стучатся в двери монополий и предлагают свое производство, или надо перестраиваться индустриально и искать лидеров, которые смогут развернуть отрасль от оборонного заказа к гражданскому рынку.

Но более эффективен следующий вариант: создание цепочки дизайн-центр - микроэлектронная фабрика. 
Дизайн-центры должны находиться на аппаратурных предприятиях, формировать спрос и обеспечивать заказы микроэлектронным фабрикам. Создание такой цепочки должно стать важной задачей для радиоэлектронной промышленности.

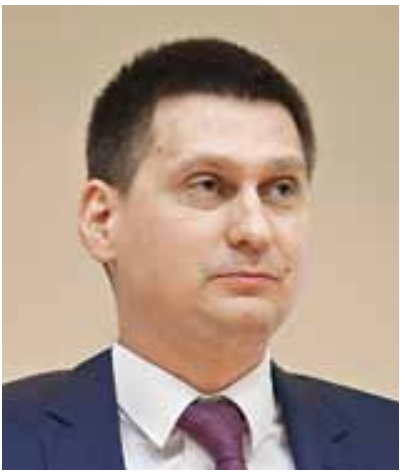

Сергей Владимирович Хохлов", директор Департамента радиоэлектронной промышленности Минпромторга России выступил с докладом "Об итогах деятельности радиоэлектронной промышиенности в 2018 году и основных задачах на 2019 20д".

\section{Задачи отрасли в 2018 году}

2017 год был не очень удачный для радиоэлектронной промышленности: общий объем производства промышленной продукции, выпущенной радиоэлектронной отраслью, снизился на 11,6\% по сравнению с 2016-м. Доля гражданской продукции составила примерно 8,2\%. Поэтому на расширенном совещании в прошлом году было принято решение проанализировать создавшуюся ситуацию, чтобы не допустить дальнейшего снижения показателей.

Перед отраслью были поставлены следующие задачи:

- обеспечить технологическую готовность к выполнению государственной программы вооружения;

- разработать программы диверсификации;

- сделать ставку на импортозамещение электронной компонентной базы.

Анализ технологической готовности радиоэлектронной промышленности к выполнению Государственной программы вооружения на период до 2027 года позволил завершить формирование второго раздела госпрограммы «Развитие ОПК» и проработать программу диверсификации предприятий радиоэлектронного комплекса для увеличения выпуска гражданской продукции.

\section{Итоги деятельности РЭП в 2018 году}

В прошлом году нам удалось довести объем производства промышленной продукции до 755 млрд руб., что выше показателей 2017 года на 14,3\% и показателей 2016-го (737 млрд руб.). В других сегментах оборонной отрасли иная ситуация: обычное вооружение - объем продукции увеличился на 1-2\%, судостроение - остался на прежнем уровне, значительное падение наблюдалось в военнокосмической промышленности.

С. В.Хохлов назначен на должность генерального директора ФГУП «ГОСНИИАС" 27 мая 2019 г.
Следует отметить также качественный рост показателей: значительно увеличился выпуск гражданской продукции, составившей 9,7\% общего объема, экспорт гражданской продукции возрос по сравнению с 2017 годом на 14\%.

\section{Государственная программа развития оборонно-} промышленного комплекса на период до 2027 года

В течение 2018 года был сформирован целый раздел госпрограммы, который представляет собой план мероприятий по технологической и производственной подготовке предприятий радиоэлектронной промышленности к выполнению госпрограммы вооружений.

Поставлена задача обеспечить выполнение государственной программы вооружений.

В настоящее время утвержден план мероприятий по направлениям:

- воздушно-космическая оборона;

- разведывательно-информационное обеспечение;

- техника связи и Асу;

- техника радиоэлектронной борьбы;

- интегрированные системы связи.

В Госпрограмме сформированы новые разделы: развития базовых технологий робототехники; создания и развития ЭКБ.

Запланированный объем финансирования НИР и ОКР по госпрограмме составит почти 140 млрд руб., что на 14\% больше по сравнению с предыдущим ее периодом. К сожалению, радиоэлектронная промышленность будет испытывать большие трудности, так как в ближайшие три года нет открытых новых работ по этой программе. Конечно, принимаются определенные меры, в частности вместе с Минфином РФ прорабатывается схема поддержки предприятий. Но я дополнительно обращаюсь к руководителям интегрированных структур с просьбой поддержать предприятия и помочь в открытии новых работ.

\section{Электронная площадка "ЭКБМаркет"}

Еще одна задача, которую мы ставили перед собой в 2018 году, - произвести оценку эффективного механизма закупки ЭКБ для образцов военной техники, гражданской продукции и предложить новые инструменты производителям и потребителям электронной техники. Надо отметить большую и важную работу ФГУП «МНИИРИП»в прошлом году запущена электронная торговоинформационная площадка "ЭКБМаркет».

Площадка предоставляет следующий набор сервисов:

- каталог ЭКБ отечественного производства;

- тУ и технические описания;

- центры испытаний;

- перспективные разработки;

- библиотека 3D-моделей. 
Действующая площадка востребована как производителями, поставщиками ЭКБ, так и ее потребителями аппаратурными предприятиями.

В дальнейшем «ЭКБМаркет» будет пополняться новыми сервисами.

\section{Развитие микроэлектроники}

В рамках поддержки государства в части развития микроэлектроники было принято решение о создании современного микроэлектронного производства с современным технологическим уровнем на пластинах диаметром 300 мм в Зеленограде на базе АО «Ангстрем-Т». Консолидация активов ГК «Ростех» и АФК "Система" позволила создать АО «Элемент», включающее в себя 20 предприятий (разработчиков микроэлектроники), общий объем выручки которых превышает 25 млрд руб. в год. Корпоративный контроль осуществляет ВЭБ. АО «Ангстрем-Т» фактически перешло под государственное управление.

Новое микроэлектронное производство будет создаваться на базе развивающихся серийных технологий АО «Ангстрем-Т» с топологическими нормами 90-250 нм (существующий производственный корпус "Ангстрем-Т», 15000 пластин / месяц диаметром 200 мм) и на базе современных технологий - 2000 пластин/месяц диаметром 300 мм.

Планируемые мероприятия по развитию нового микроэлектронного производства нашли отражение в подготовленном проекте комплексной целевой программы «Развитие микроэлектроники на период до 2030 года» и в программе "Создание и развитие дизайн-центров, центров коллективного проектирования».

Программа развития микроэлектроники содержит три подраздела: развитие производства и технологий микроэлектроники, создание систем автоматизированного проектирования и специальное технологическое оборудование.

Со следующего года планируется поддержка программы по развитию дизайн-центров и центров коллективного проектирования, разработаны конкретные предложения по развитию дизайн-центров. Предполагается, что к 2027 году будет создано более 12 тыс. рабочих мест дизайнеров и 5 центров коллективного проектирования.

\section{Диверсификация. Госпрограмма. \\ Фонд развития промышленности}

В соответствии с поручением Президента Российской Федерации (ПР-1845) перед предприятиями ОПК поставлена задача довести к 2030 году выпуск гражданской продукции в общем объеме продукции до 50\% и более.

Сейчас в радиоэлектронной отрасли доля гражданской продукции составляет примерно 9\%. Для примера: в авиастроении этот показатель превышает 15\%, в судостроении - 20\%, в сегменте обычных вооружений - более $25 \%$.

Как выполнить это поручение? Откуда брать деньги?

"Основные источники финансирования прежние - субсидии и займы. Но обращаю внимание всех присутствующих на совещании на то, что ФРП (Фонд развития промышленности) предоставляет займы предприятиям ОПК по программе «Конверсия". В 2017 году их объем составил 5,5 млрд руб. Общая сумма займов, выданных в 2018 году, превысила 27,6 млрд руб. Что касается условий, то при сумме займа на пять лет 0,2-0,75 млрд руб. (общий бюджет проекта 0,4 млрд руб.) - 1\% на первые три года и 5\% на оставшийся срок.

\section{Национальные проекты.}

\section{Реестр отечественной радиоэлектроники}

В 2018 году Правительством РФ по поручению Президента РФ было сформировано 12 национальных проектов. Во многих из них мы должны участвовать: цифровая экономика; экология; производительность труда и поддержка занятости; образование; наука; здравоохранение; жилье и городская среда; демография; культура; безопасные и качественные автомобильные дороги.

Сегодня основная задача, стоящая перед отраслью, формирование заказов на гражданском рынке, разработка продуктовых проектов. От решения этой задачи зависит не только выполнение программы диверсификации, но и перспективы нашей промышленности.

В целях дальнейшего развития радиоэлектронной промышленности разработан проект постановления Правительства Российской Федерации "О мерах стимулирования производства радиоэлектронной продукции на территории Российской Федерации при осуществлении закупок товаров, работ, услуг для обеспечения государственных и муниципальных нужд". Предполагается создание Единого реестра российской радиоэлектронной продукции и установление правил допуска продукции иностранного производства на российский рынок. При этом важная роль отводится отдельным ассоциациям по видам продукции, к формированию которых мы приступили.

\section{Задачи на 2019 год}

К задачам на текущий год относятся:

- диверсификация производственных предприятий и организаций радиоэлектронной промышленности;

- участие предприятий и организаций в реализации национальных проектов;

- приоритетное развитие микроэлектронных производств (создание дизайн-центров).

Перечисленные задачи должны быть включены в проект Стратегии развития электронной и радиоэлектронной промышленности до 2027 года. 


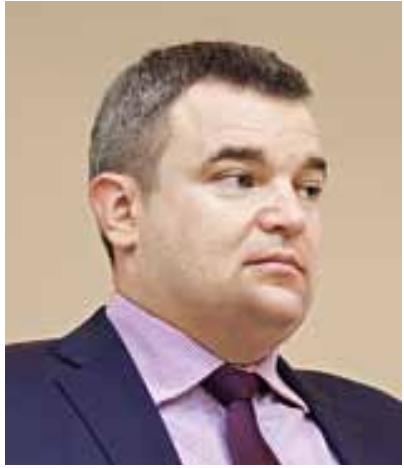

С докладом "О мерах государственной поддержки создания, развития функционирования дизайн-центров" выступил заместитель директора Департамента радиоэлектронной промышленности Минпромторга России Василий Викторович Шпак".

«В докладах, которые были представлены сегодня, названы все цифры и ориентиры, поставленные перед отраслью руководством страны. В продолжение доклада С. В. Хохлова я расскажу о тех мерах, которые надо принять, и о шагах, которые мы должны сделать для достижения этих целей».

Сегодня, в очень непростое для радиоэлектронной промышленности время, когда государство нашло деньги на развитие современного микроэлектронного производства, очень остро стоит вопрос загрузки создаваемых мощностей.

Микроэлектроника сама рынки не образует. Для формирования рынка микроэлектронных изделий необходимо расширить ниши производителей радиоэлектронного оборудования. Более того, особенно в чувствительных и значимых для нас областях следует обеспечить доминирование на внутреннем рынке отечественного производителя. Одновременно надо помнить и о развитии экспортного потенциала.

Наши приоритеты - национапьная безопасность и безопасность критической информационной инфраструктуры. В век информации роль информационнокоммуникационных технологий, которые обеспечиваются и поддерживаются радиоэлектронным оборудованием, переоценить невозможно. Значимость информационных технологий в 21 веке можно сравнить с актуальностью атомных технологий в 20 веке.

Наша цель - развитие микроэлектронной промышленности как основы суверенитета страны. Для ее достижения предстоит решить следующие задачи:

- создание и загрузка новых производственных мощностей микроэлектронной промышленности;

- доминирование отечественных производителей на внутреннем рынке и выход на зарубежные рынки.

В. В. Шпак назначен на должность директора Департамента радиоэлектронной промышленности Минпромторга России 28 мая 2019 г.

Рис. 1. Дорожная карта
В настоящее время разработана соответствующая дорожная карта (рис. 1). Периоды 2019-2020 и 2021-2024 годов - это создание задела. Сегодня нашей отрасли предоставляется возможность активно участвовать в реализации национальных проектов, обеспечив поставку имеющихся решений. Для предприятий отрасли это не только реальная возможность запустить рыночные механизмы, но и заложить основу диверсификации производств ОПК. А для поставщиков, которые уже производят и продают свою продукцию, это новые возможности для расширения присутствия на гражданских рынках.

К 2022-2023 годам (см. рис. 1) ситуация должна выправиться, а в особо чувствительных областях прогнозируется преобладание продукции отечественных производителей на внутреннем рынке. Но без нормативной поддержки, способствующей закрытию ниш для иностранных конкурентов и открытию ниш для российских предприятий на внутреннем рынке трудно добиться доминирования отечественного производителя.

Производство новых продуктов. Наряду с новым микроэлектронным производством в Зеленограде к2021 году заработает в полную силу НПП «Исток». Наличие двух таких площадок, с одной стороны, дает возможность обеспечить всю линейку технологических возможностей и потребностей для нашей отрасли, а с другой - остро поставит вопрос о загрузке этих производств, то есть нужны новая продукция, новые разработки и проекты.

Именно поэтому вопросы расширения мощностей действующих дизайн-центров и создание новых, организации дополнительных высокотехнологичных рабочих мест приобретают важное и главенствующее значение.

На сегодня совокупный потенциал разработок в сфере отечественной микроэлектроники - не более 500 проектов в год. Простой подсчет показывает, что для загрузки фабрик и вовлечения страны в цифровую экономику нам необходимо до 2000 (и более) проектов в год.

Для этого потребуется не менее 250 новых дизайнцентров и значительное расширение существующих производственных мощностей, а также создание не менее пяти центров коллективного проектирования.

Пиан применения отечественной ЭКБ в аппаратуре (рис. 2) предполагает, что в 2025-2030 годах, по мере запуска нового микроэлектронного производства по современным технологическим нормам, будет реализована
2019-2020 гг. $\quad$ 2021-2024 гг.

Создание продуктов для нац. проектов

2025-2030 гг.

\begin{tabular}{|c|c|c|}
\hline \multicolumn{2}{|c|}{ 2021-2024 гг. } & 2025-2030 гг. \\
\hline Создание пр & Ктов & Выход на зарубежные рынки \\
\hline \multicolumn{3}{|c|}{ Доминирование на отечественном рынке } \\
\hline
\end{tabular}




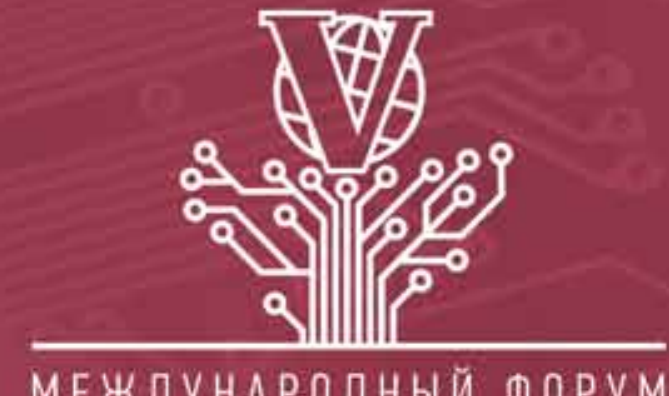

МЕЖДУНАРОДНЫЙ ФОРУМ

МИКРОЭЛЕКТРОНИКА 2019

30 сентября - 5 октября

Республика Крым,

г. Алушта

\section{V Юбилейный Международный Форум «Микроэлектроника 2019» -}

ключевое событие года в области микроэлектронных технологий

V Научная конференция «ЭКБ и микроэлектронные модули»

V Деловая программа $\quad \mathbf{V}$ Демонстрационная зона

V Фестиваль инноваций

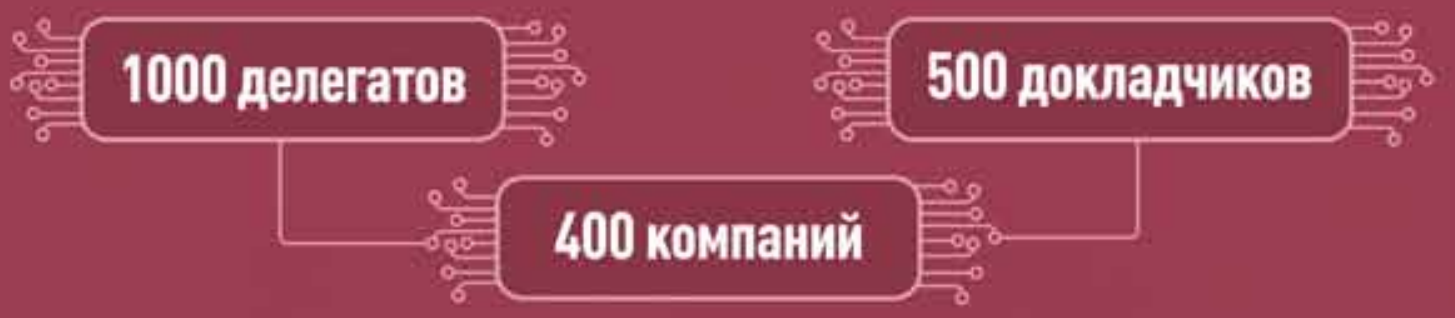

За все 4 года успешной работы

ПРИ ПОДДЕРЖКЕ

\section{МИнПРомторг $\triangle$ России

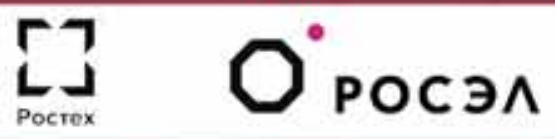

ОРГАНИЗАТОРЫ

Генеральный информационный партнёр

\section{III) прогресс \& ниимэ (3) МИЭт}

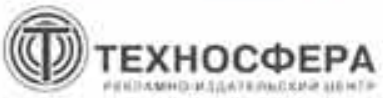

Oператтор Форума: Компания «ПрофККонференции» • Тел.: +7 (495) 641-57-17 • E-mail: info@microelectronica.pro Подробная информация и регистрация участников на официальном сайте Форума: microelectronica.pro 


\begin{tabular}{|c|c|c|c|}
\hline & 2019-2020 & 2021-2024 & 2025-2030 \\
\hline $\begin{array}{l}\text { Степень локализации } \\
\text { ЭКБ в аппаратуре }\end{array}$ & Низкая & Средняя & Высокая \\
\hline $\begin{array}{l}\text { Этапы внедрения } \\
\text { ЭКБ в аппаратуру }\end{array}$ & $\begin{array}{c}\text { Наша разработка, } \\
\text { иностранное } \\
\text { производство }\end{array}$ & $\begin{array}{c}\text { Наша разработка, } \\
\text { наше производство } \\
\text { >90 нм / GaAs }\end{array}$ & $\begin{array}{c}\text { Наша разработка, } \\
\text { наше производство } \\
\text { > } 28 \text { нм / GaAs }\end{array}$ \\
\hline $\begin{array}{l}\text { Создание новых рабочих } \\
\text { мест дизайнеров }\end{array}$ & 1000 & 4000 & 7000 \\
\hline $\begin{array}{l}\text { Создание центров } \\
\text { коллективного пользования }\end{array}$ & 1 & 4 & - \\
\hline
\end{tabular}

Рис. 2. План применения отечественной ЭКБ в аппаратуре на 2019-2030 годы высокая степень локализации отечественной ЭКБ в радиоэлектронной аппаратуре. Все это влечет за собой создание дополнительных рабочих мест дизайнеров - по плану Минпромторга России - не менее 20000.

Параллельно с Минобрнауки РФ ведутся переговоры о создании таких дизайн-центров на базе ведущих вузов в различных регионах нашей страны. Ожидается, что это поможет решить кадровую проблему. В настоящее время уровень и количество молодых специалистов, которых готовит наша высшая образовательная система, к сожалению, не обеспечивают даже воспроизводимость и поддержание штатной численности в отрасли.

Обращаясь к производителям аппаратуры, в первую очередь к представителям компаний, которые уже работают на гражданском рынке, В.В.Шпак констатировал: «Локализация - это наш ключ к расширению существующих рыночных ниш, и государство готово эти ниши открывать для вас. Условие одно - готовность и желание расширять ваши технологические цепочки вплоть до уровня разработки изделий микроэлектроники. В процессе формирования в ваших структурах подразделений по дизайну микроэлектроники государство готово оказать существенную помощь и поддержку: предполагается субсидирование затрат на создание инфраструктуры».

В этом процессе важная роль отводится отраслевым ассоциациям. В частности, зарегистрирована ассоциация «Консорциум дизайн-центров и предприятий радиоэлектронной промышленности". В.В.Шпак пригласил всех, кто связывает свое будущее с разработкой микроэлектронных изделий, принять участие в работе ассоциации: «консолидируя отраслевую позицию, выдвигая общую экспертную позицию по принятию нормативных актов, таможенному регулированию и всему остальному, мы сможем эффективно двигаться вперед".

По инициативе Департамента радиоэлектронной промышленности и Минпромторга России разработаны меры государственной поддержки создания, развития и функционирования дизайн-центров, в частности в сфере наиогового и таможенно-тарифного стимулирования:
- льготные ставки по отчислениям с ФОТ;

- нулевая ставка всех налогов для организаций российской микроэлектроники;

- прогрессивная шкала ставок таможенных пошлин, прямо пропорциональная степени конструкторской агрегации оборудования.

Самая распространенная мера поддержки при формировании структур и создании дизайн-центров - субсидии, причем 70\% затрат на формирование инфраструктуры дизайн-центра государство берет на себя. При этом оно будет требовать 30\% софинансирования и обеспечения полной загрузки дизайн-центров. Эти меры поддержки предоставляются не только предприятиям, работающим в гражданской сфере, но и компаниям, которые традиционно обеспечивают национальную безопасность, чтобы ускорить процессы диверсификации.

В заключение В.В.Шпак обратился к участникам совещания со словами: "Нам надо менять подход, надо реально объединяться. Только вместе, только сообща мы сможем конкурировать с иностранными игроками, вендорами, которые ведут активную охоту на нашем внутреннем рынке. Их возможности, даже по отдельности, сейчас выше, чем наши совокупные возможности. Поэтому эффективное консолидированное движение вперед должно стать нашим общим вектором развития радиоэлектронной отрасли».

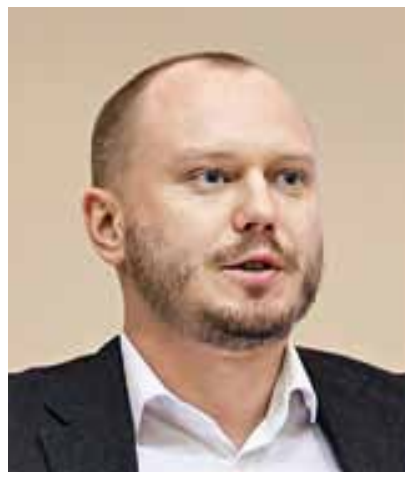

"Oтраслевые ассоциации как эффективный инструмент взаимодействия власти и бизнеса" - тема доклада Андрея Анатольевича Безрукова, президента Ассоциации разработчиков и производителей электроники (АРПЭ).

Ассоциация создана в 2017 году с целью 


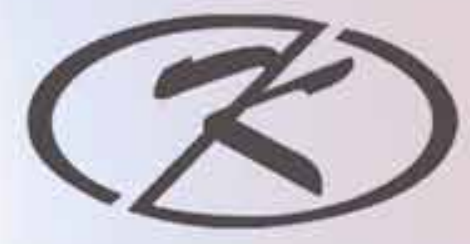

располагает парком нового высокоточного оборудования для механической обработки и выполняет следующие виды работ:изготовление деталей, пресс-форм, штампов, технологической сснастки, а также других металлоизделий по чертежам, образцам или зскизам заказчика.

\section{ЗАГОТОВИТЕЛЬНЫЙ УЧАСТОК:}

- ленточно-пильный станок модели ВS 360 А (Китай);

- ножницы тильотинные СТД-9АН (6×2500) (Беларусь);

- оборудование для гидроабразивной резки Milestone 1720 (Италия).

ПРЕССОВЫЙ УЧАСТОК:

- прессы Yangli JH21-25B, Yangli JC23-6,3D, Yangli J23-16D (Китай).

\section{ТЕРМИЧЕСКИЙ УЧАСТОК:}

- печи СДО-4.8.3/11,5 и СДО-4.8.3/8 (Россия);

- установка для нагрева токами высокой частоты В4-60АВ (Россия).

\section{СЛЕСАРНО - СБОРОЧНЫЙ УЧАСТОК:}

выполнение различных работ по сборке узлов и изделий,

а также выполнение широкого спектра слесарных работ.

\section{ФРЕЗЕРНЫЙ УЧАСТОК:}

оборудование компании DMG MOR!

- пятикоординатный обрабатывающий центр с возможностью силового фрезерования с поворотом стола - DMU 75 mопоB LOCK (Германия), - трехкоординатный фрезерный станок модели DMC $635 \mathrm{~V}$ ecoline (Россия).

\section{УЧАСТОК ЭЛЕКТРОЭРОЗИОННОЙ ОБРАБОТКИ:}

- станки компании Sodick Moдели AG40L, ALC 400G, AP 250 oil (Япония); оборудование для получистовой обработки марки АРТА (Россия).

\section{ТОКАРНЫЙ УЧАСТОК:}

- токарно-фрезерный станок DMC DL6 TMH (Южная Корея);

- токарный прутковый полуавтомат NEXTURN SA2OPY (Южная Корея;

- CNC-универсальный станок СТX 310 ecoline (Россия);

- прецизионный токарно-винторезный станок SAMAT 400S/S класса точности А (Россия);

- универсальный токарный станок с минипрограммным (оперативным) управлением SAMAT 400 XC (Россия).

\section{КОНТРОЛЬНЫЙ УЧАСТОК:}

- профильный проектор Nikon V12BDC (Япония);

- контрольно-измерительная машина

CONTURA G2 7/7/6 Direct (Германия).

\section{ШЛИФОВАЛЬНЫЙ УЧАСТОК:}

- плоскошлифовальные станки лШ;

- круглошлифовальный станок с ЧПУ (EGP-3860CNC):

- плоскошлифовальный станок с чПУ(МК7363);

- униеерсальный заточной станок (CM-A).

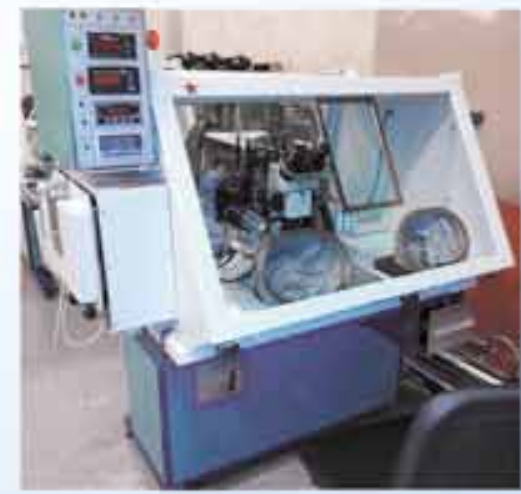

Предлагает потребителю оборудование собственного производства:

\section{- ПОЛУАВТОМАТ ГЕРМЕТИЗАЦИИ МИКРОСХЕМ 03КС-700-2М}

предназначен для герметизации шовной контактной сваркой керамических, металлонерамических и металлостеклянных корпусов микросхем типа 2 и 4 no rOCT $17467-79$.

Полуавтомат отличается от аналогов наличием термовакуумного шкафа, обеспечивающего предварительную откачку изделий с прихваченной крышкой, выдержку ихв среде азота при температуре $50 \ldots 1009 \mathrm{C}$ перед герметизацией, а также контроль точни росы в рабочем обьеме скафандра полуавтомата. 
развития отраслевого инженерного и бизнес-сообщества и выстраивания взаимодействия с органами государственной власти. Сегодня Ассоциация объединяет более 50 активно развивающихся компаний, ежегодная выручка Ассоциации составляет 50 млрд руб., создано 10000 рабочих мест.

В составе АРПЭ сформирован ряд комитетов, представляющих основные направления деятельности ассоциации: комитет по регулированию внутреннего рынка, нацеленный на значительное увеличение доли отечественных производителей на российском рынке, международный комитет, содействующий выходу российских компаний на зарубежные рынки, комитет по контрактному производству, а также кадровый комитет, осуществляющий профориентационную деятельность в школьной и университетской средах и отвечающий за развитие кадрового потенциала компаний - участников АРПЭ.

Компании, которые входят в ассоциацию, готовы уже сегодня создать масштабный спрос на российские ЭКБ, материалы, технологические решения и на российское системное ПО. Со стороны бизнеса АРПЭ готова поддерживать государство в развитии и укреплении его суверенитета и глобального лидерства в области цифровых решений.

А.А. Безруков в заключение сообщил, что АРПЭ совместно с компанией «русСОФТ» планирует сделать несколько проектов комплексных решений для умного города, а также работает над подготовкой соглашения с одной из крупнейших компаний, которая занимается инфраструктурой «Цифровой экономики».

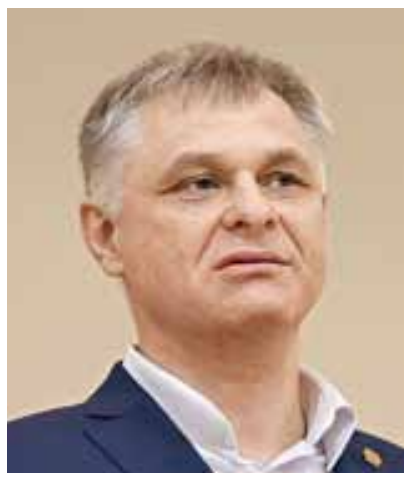

С докладом «Cmpameгия развития гражданского рынка с испопьзованием мер государственной поддержки" выступил генеральный директор АО «ПКК Миландр" Михаил Ильич Павлюк, который рассказал об опыте разработки и внедрения аппаратно-программной платформы энергоучета

"Инфосфера».

Сегодня на рынке востребованы не микросхемы, не технологии, не материалы, а решения. Кто предлагает решения, тот предъявляет требования к программному обеспечению, материалам, технологиям и т. д. На рис. 3 представлены две пирамиды: компетенций и формирования прибыли. Наибольшую прибыль получает разработчик программного обеспечения. При выходе на гражданский рынок надо понимать, что тот, кто владеет решениями,

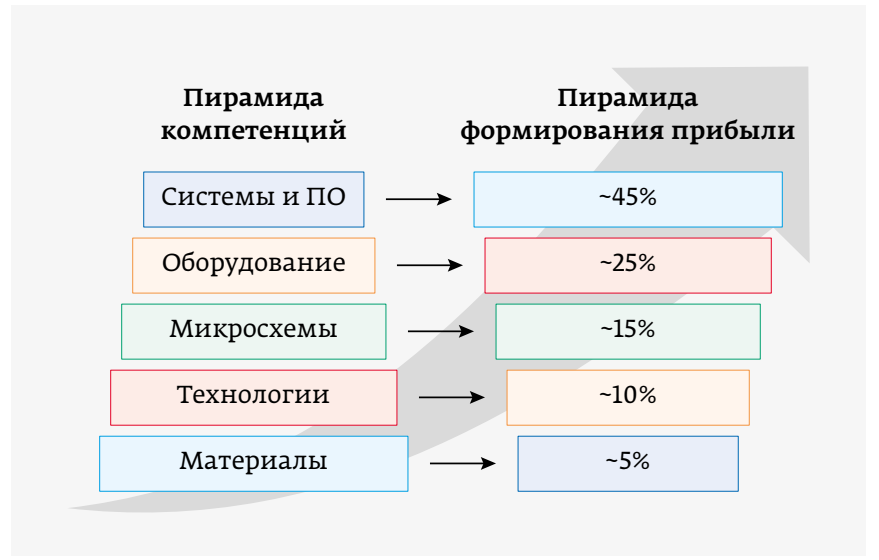

Рис. 3. Стратегия увеличения прибыли

тот может использовать ваши микросхемы или приборы в своем решении и обеспечивает вам прибыль.

Поначалу мы не понимали этого, поэтому от микросхем направились в сторону оборудования, то есть к производству электрических счетчиков. Мы предложили микросхему, которая по своим возможностям превосходила решения конкурентов.

Но наши микросхемы оказались дороже примерно в четыре раза по сравнению с теми, которые предлагали на российском рынке иностранные производители. Компенсировать убытки, возникающие в результате применения нашей дорогостоящей элементной базы, можно только за счет снижения прибыли приборостроителей. Но они не готовы были делиться прибылью. Указанная в пирамиде прибыль (см. рис. 3) 15\% - это максимальная прибыль, на самом деле, 10\% и менее. А если микросхема не достигнет объема продаж 1 млн шт., то и говорить о прибыли не придется.

В поддержку производителей было принято постановление о 30\%-ных преференциях, обязывающее поставщиков решений делиться прибылью с производителями микросхем, технологий и материалов (если продукт выпускается на бюджетные средства, то прибыль должна делиться по всей цепочке).

Что касается установления факта, сколько в решении оборудования иностранного и российского, то мы предлагаем считать отечественными те продукты, в которых стоят наши процессоры и контроллеры, определяющие функционирование системы.

Когда мы выяснили, что производители решений не будут делиться с нами прибылью, мы стали создавать платформы, а затем и приборы, путь развития представлен на рис. 4. Наша компания специализировалась на производстве микросхем, но после принятия решения о выпуске счетчиков был сформирован дизайн-центр приборов. Первый созданный нами счетчик был конкурентоспособным. Но производство отказалось от нашего 


\section{Микросхемы}

- Малые объемы выпуска

- Высокая удельная цена

- Недоверие потребителя

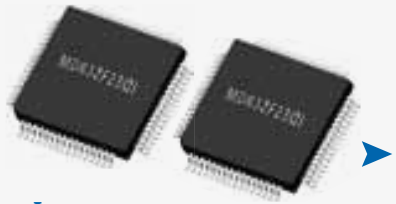

- Функционал

с резервом развития

\section{Приборы}

- Необходима линейка счетчиков

- Множественная сертификация

- Необходимы

коммуникационные приборы

- Создан многофункциональный прибор учета электроэнергии (ретрансляция, отключение нагрузки, гетерогенная и MESH-интеграция)

Рис. 4. Развитие производства в АО «ПКК Миландр»

прибора (боялись, что мы выйдем со своим решением на рынок счетчиков), и нам ничего не оставалось, как двигаться далее. Мы создали следующий прибор. Оказалось, что надо делать не просто счетчик, а прибор со всеми комплектующими (обвязка, средства сбора и передачи информации и т.д.), нужны периферия и программное обеспечение. Тогда и был создан центр программного обеспечения.

\section{Система}

- Многообразие

протоколов

передачи данных

- Реализованы технические решения (различные

каналы передачи данных: силовые, слаботочные провода, радиоканал, гетерогенные, MESH-сети)

- Реализованы требования потребителя (от монодо комплексного энергоучета)

\section{ПО}

- Многоуровневое пО

- Наращивание вычислительных мощностей (мощные ЦОДы)

- Отсутствие стандартов

- Отсутствие нормативной базы

- Создана доверенная информационная система

В результате мы использовали разработанные ранее конкурентоспособные решения и создали систему, которая определяет наш рынок сегодня.

счетчик собирает информацию с любых устройств и передает ее в центр управления. Теперь перед нами стоит задача переходить на новый уровень, то есть создавать такое оборудование, которое может работать в автоматизированных системах, например, умный дом.

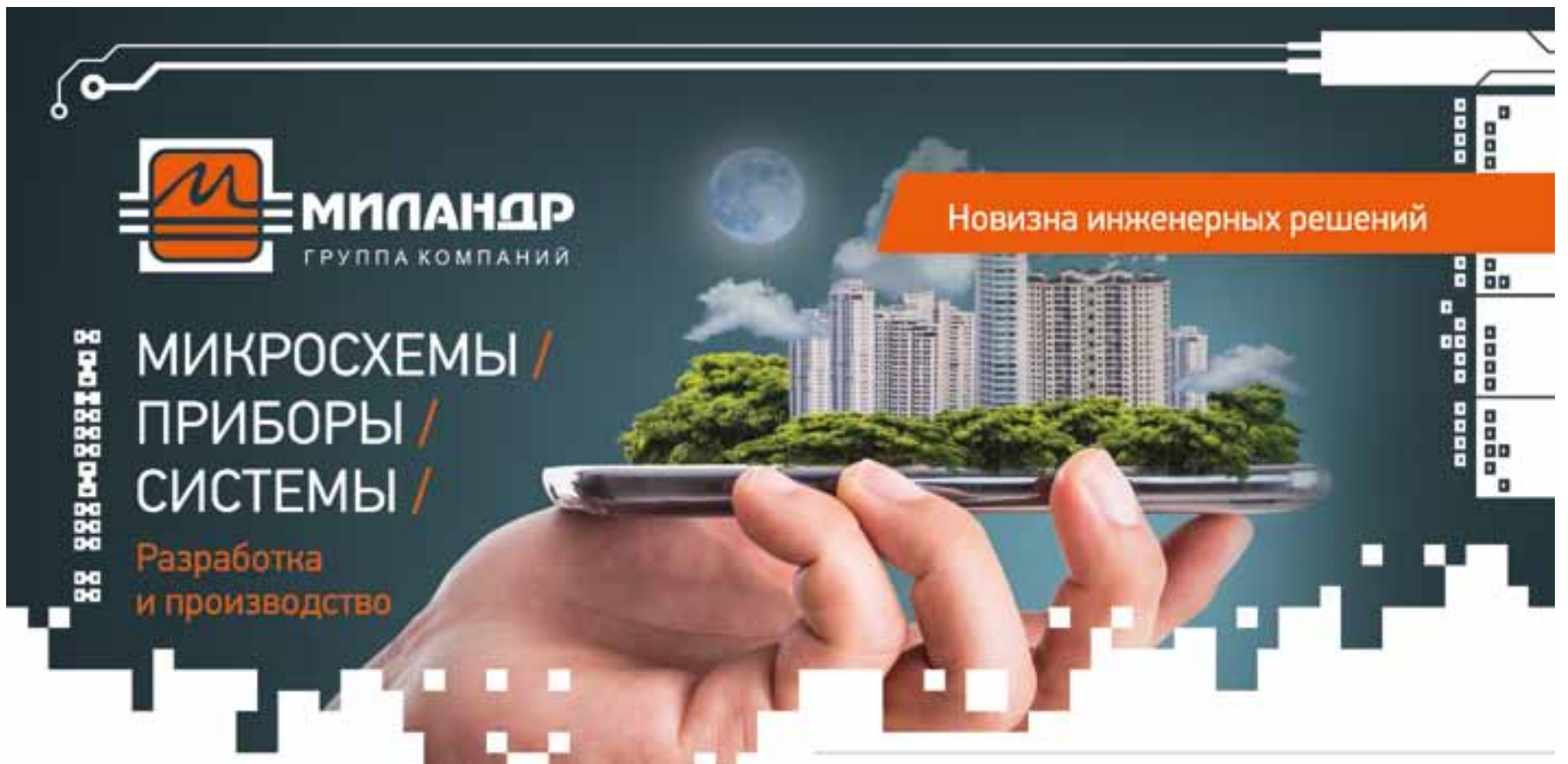

ИНФОРМАЦИОННАЯ СИСТЕМА ИНФФОСФЕРА

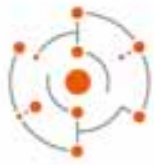

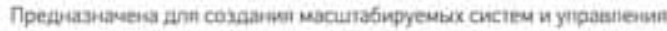

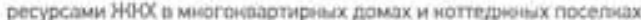

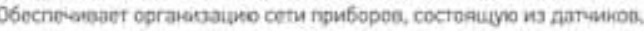

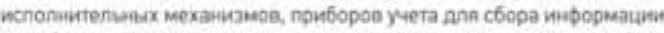
ИНФРАСТРУКТУРА УПРАВАЕНИЯ РЕСУРСАМИ o nuтребпнемых ресурсах, а таноме сетевs $\alpha$ монцентрируоцих устройств 